\title{
SOIL-TRANSMITTED HELMINTHS IN CHILDREN WITH CLINICAL SYMPTOMS OF INFECTION
}

B. P. Rudramuneswara Swamy, Sreedhara H.G, Mahanthesh S, Vijaykumara H.G

1. Assistant Professor, Department of Microbiology, Academy of Medical Sciences, Pariyaram, Kannur, Kerala.

2. Associate Professor, Department of Microbiology, Hassan Institute of Medical Sciences, Hassan, Karnataka.

3. Associate Professor, Department of Microbiology, Indira Gandhi Institute of Child Health, Bangalore, Karnataka.

4. Associate Professor, Department of Community Medicine, Sapthagiri Institute of Medical Sciences, Chikkasandra, Bangalore, Karnataka.

\section{CORRESPONDING AUTHOR:}

Dr. B.P. Rudramuneswara Swamy, No. 82, 17th Cross, 32 ${ }^{\text {nd }}$ Main Road, $6^{\text {th }}$ Phase, J.P Nagar, Bangalore - 560078,

Karnataka, India.

E-mail: bprswamy@yahoo.com

ABSTRACT: The study was conducted to know the prevalence of soil-transmitted helminths (STH) in children aged 1-14 years attending outpatients and inpatients from both urban and rural background. Out of the 550 stool samples examined, 450 were from the study group and 100 from the control group. All the 450 children of the study group presented one or more of the classical symptoms like abdominal pain, low grade fever, diarrhoea, dysentery, constipation and pica. Hundred children from the control group did not have any classical symptoms. Thirty five per cent from the study group and 21 per cent from the control group were found positive for one or more of the helminthic infection.

The prevalence of Ascaris lumbricoides, Trichuris trichiura, Ancylostoma duodenale \& Necator americanus (hookworm), Hymenolepis nana and Enterobius vermicularis were 27\%, $15 \%, 0.4 \%, 2 \%$ and $0.22 \%$, respectively in the study group and $15 \%, 10 \%, 4 \%, 2 \%$, and $2 \%$, respectively in the control group. Strongyloides stercoralis was not found either in the study or control groups. Helminthic infections were more common in 7-9 years of age group, urban children with low socio-economic strata, and with male preponderance. Majority of children who harboured STH were suffering from abdominal pain and low grade fever.

Total 450 clinical samples (control group) examined by direct wet mount, saturated salt floatation, and formalin-ether sedimentation; and only 391 samples examined by Kato-Katz semiquantitative techniques. Twenty six per cent positive by direct wet mount, $35 \%$ by both saturated salt floatation and formalin-ether sedimentation whereas $38 \%$ of the samples were found positive by Kato-Katz semiquantitative technique. In conclusion, concentration techniques like saturated salt floatation and formalin-ether sedimentation are the best diagnostic tools to get authentic and reliable results and to rule out fallacious inference caused by relying only on direct wet mount preparation, whereas Kato-Katz, a semiquantitative technique is the best diagnostic method to know the prevalence and intensity of the STH infection. This technique is simple, rapid, reliable, and mild infections can also be detected. No special equipment and expertise are needed and it can be performed in the field survey.

KEYWORDS: Soil-Transmitted Helminths, Paediatric Age Group. 
INTRODUCTION: The soil-transmitted helminthic (STH) infections are caused by helminths like Ascaris lumbricoides, Ancylostoma duodenale \& Necator americanus (hookworm), Trichuris trichiura and Strongyloides stercoralis. The global burden of roundworm, hookworm and whipworm is 1000 million, 900 million and 800 million, respectively, whereas in the developing world it is estimated to be 700 million, 800 million and 500 million respectively. At any one moment in the world, more than 2 billion people are infected with STH infections. The sustained infection and disease burden cause effects on the development of the child, educational achievement, reproductive health, adult productivity and ultimately socio-economic development. According to the World Development Report of 1993, intestinal worm infection is the leading cause of morbidity in school children, accounting for 10.6 and 9.2 million of Disability-Adjusted Life Years (DALYs) lost in males and females, respectively. ${ }^{1}$

The provision of safe drinking water, sanitary latrines, and sanitary methods of refuse disposal, adequate nutritious diet, proper housing, and health education to the rural and urban dwellers reduce the incidence and prevalence of STH infection. They should also guide to lead a healthy life style with the available limited resources. Regular chemotherapy in school age children is the most cost-effective public health intervention.

The impact of STH on health and economy has been largely underestimated. STH infection is a major public health problem in developing countries and less significance has been given to it, because its clinical presentations are not acute. The worm infection is prevalent in school-going children. Directly or indirectly it causes malnutrition, growth retardation, anaemia and impaired cognition. The morbidity of these parasitic infections can be reduced remarkably by proper diagnosis and treatment. Therefore, this study was undertaken with the following objectives.

- To study the STH in clinically suspected cases in the paediatric age group of 1-14 years.

- To study the association of STH with age, sex and economic status of the patients.

- To evaluate the relative merits of diagnostic methods like direct wet mount with concentration methods, such as saturated salt floatation, formalin-ether sedimentation and Kato-Katz semiquantitative techniques.

METHODS: Four hundred and fifty stool specimens from children of 1 to 14 years of age, attending the outpatient and inpatient departments, suffering from one or more of the classical symptoms like abdominal pain, diarrhoea, dysentery, constipation, low grade fever and pica and 100 control group without any classical symptoms of STH were collected. The study was undertaken from May 2003 to May 2004 in the Department of Microbiology, Bangalore Medical College, Bangalore, Karnataka, India. Out of 450 samples 270 were males and 180 were females, and 327 patients were from urban area and 123 were from rural area with different socioeconomic strata.

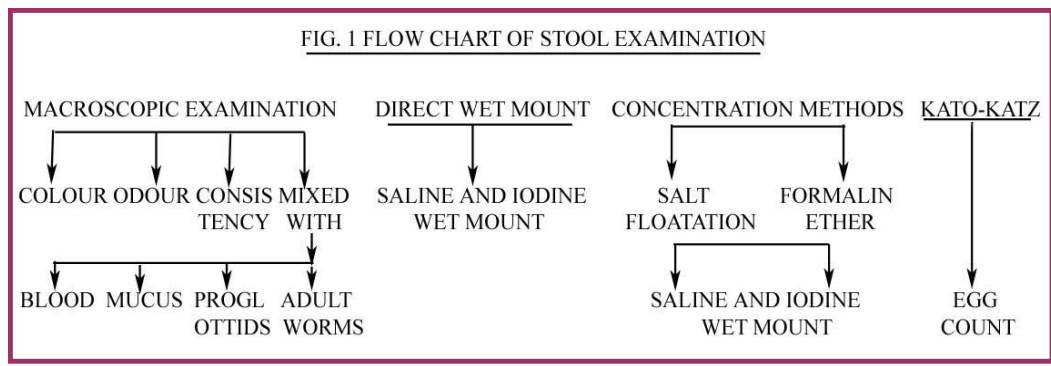

Fresh faecal specimens were collected in a clean wide-mouthed, leakproof plastic container. The majority of specimens were submitted to the laboratory within 30 
minutes of passage. Patients were advised not to contaminate the specimen with urine or water. The specimens thus collected were examined in the following methods within two hours as per the recommended procedures. The samples were subjected to macroscopic and microscopic examinations for eggs, larva, or whole adult worm, saturated salt floatation, formalin-ether sedimentation and Kato-Katz techniques. Kato-Katz, a semiquantitative technique is used for STH and schistosomiasis epidemiology and control work and is recommended by WHO (Figure 1 and Figure 2). ${ }^{3}$

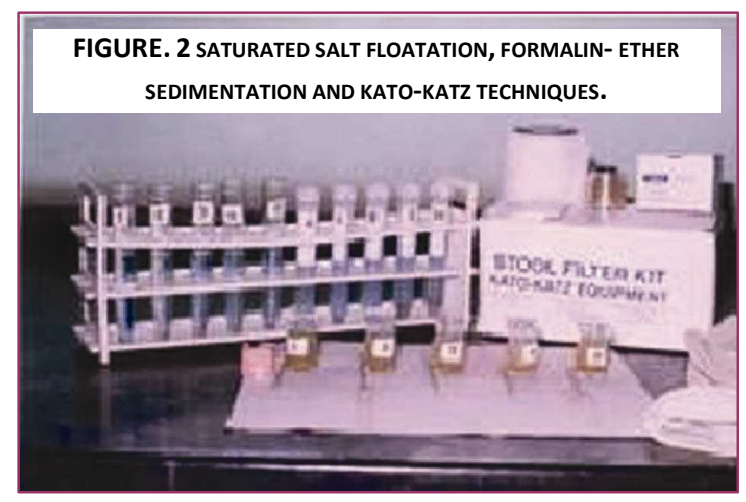

PROCEDURE OF KATO-KATZ METHOD (CELLOPHANE FAECAL THICK-SMEAR):

Pieces of nylon screen measuring 30-35 mm were cut. The hydrophilic cellophane of 30-35 $\mathrm{mm}$ were cut and placed in a jar containing glycerol and left for at least 24 hours. To increase the visibility of the eggs, $1 \mathrm{ml}$ of $3 \%$ aqueous methylene blue was added to the glycerol solution. The cellophane strips were soaked in $50 \%$ glycerol-methylene blue solution for 24 hours before use. A small amount of faeces was transferred onto a piece of filter paper. The mesh was pressed on the top of the faecal sample. By using the flat-sided spatula the stool sample was collected from the nylon mesh by scraping the upper surface of the screen. The template was placed on a clean microscopic slide. Scraped faecal material was filled in the hole of the template with an applicator, which holds $41.7 \mathrm{mg}$ of faecal material. The template was removed carefully so that all the faecal material was left on the slide and none was sticking to the template. With the help of fine forceps, the cellophane strip was soaked in glycerol and applied on the faecal material. With the help of another microscopic slide, the preparation was pressed enabling smooth and even spread of material. When the excess glycerol was present on the surface of the cellophane, it was wiped with a piece of filter paper. The microscopic slide was gently removed sideways from the cellophane in such a way that the cellophane was not separated.2,3

READING OF KATO-KATZ PREPARED SLIDES (CELLOPHANE FAECAL THICK SMEAR): After preparation the slide was kept in an incubator at $40{ }^{\circ} \mathrm{C}$ for 30 minutes. Then the slides were wiped with a blotting paper and observed under microscope. The smears (cellophane faecal thick-smear) were examined in a systematic manner and number of eggs of each species in every slide was counted and noted. Later a multiplication factor, 24 was used to estimate the number of eggs per gram of faeces. The result was noted down, eggs per slide, eggs per milligrams of faeces for each child separately. From the observations of the eggs, precise estimation of intensity of infection and prevalence of the species in the study population was interpreted. ${ }^{3}$

CULTIVATION OF ASCARIS LUMBRICOIDES AND TRICHURIS TRICHIURA EGGS IN THE SOIL. The positive stool samples of A. lumbricoides and T. trichiura were taken into a plastic container with small amount of soil and water, and lid of the container was just covered, but not completely closed. Everyday moisture was maintained by adding a little amount of water for about 4 to 7 weeks. The development of embryo within the eggs was observed everyday under the low and high power microscope. 
RESULTS: A total of 550 stool samples were examined, of which 450 were from the study group and 100 were from the control group. Thirty five per cent from the study group and 21 per cent from the control group were found positive for one or more helminthic infection (Figure 2). Fifty four per cent of males and 46 per cent of females were positive for one or more STH in the study group, whereas in the control group, the positivity was $13 \%$ and $8 \%$ in males and females respectively. However, it was not statistically significant in both the study and the control groups ( $\mathrm{P}-0.07$ and $\mathrm{P}-0.57$ respectively).

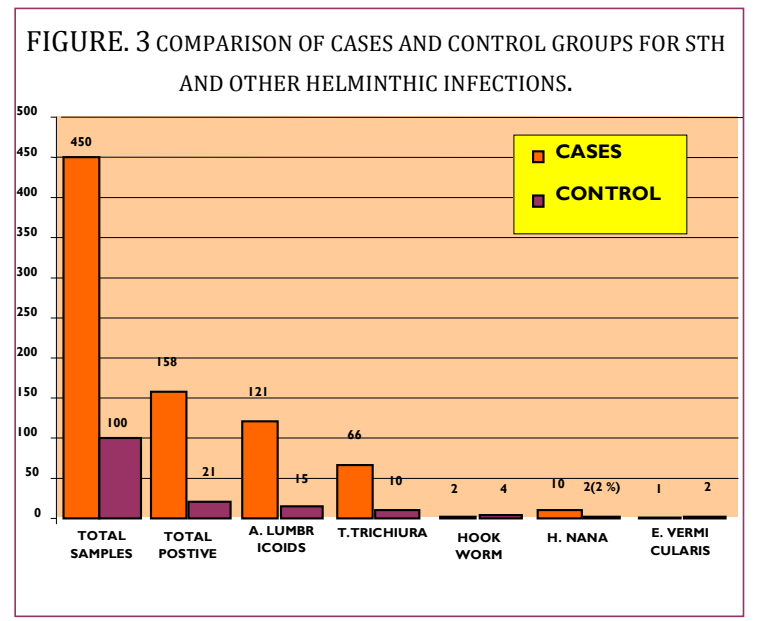

A. lumbricoides was the commonest worm followed by $T$. trichiura, $H$. nana, Hookworms and E. vermicularis in the study group (Figure 3). On the other hand, in the control group, the prevalence of Hookworms, H. nana and E. vermicularis are significantly more than the case group (Figure 3). Mixed infections were seen in 38 children (24\%), of which double infections found in $35(22 \%)$, triple in $4(3 \%)$ and quadruple infections in 1 $(0.22 \%)$ in the study group. S. stercoralis was not found either in the study or the control groups. The present study correlates relatively with the study of Bora et al. (2001) who also used WHO sampling design methodologies and Kato-Katz technique in school children (Table 1).

\begin{tabular}{|c|c|c|}
\hline \multicolumn{3}{|c|}{ TABLE 1. COMPARATIVE STUDY OF } \\
DISTRIBUTION OF STH \\
\hline TYPE OF WORMS & $\begin{array}{c}\text { Bora } \\
\text { et al }^{4} \\
(2001)\end{array}$ & $\begin{array}{c}\text { PRESENT } \\
\text { STUDY (2004) }\end{array}$ \\
\hline A. LUMBRICOIDES & $26 \%$ & $27 \%$ \\
\hline T. TRICHIURA & $25 \%$ & $15 \%$ \\
\hline HOOKWORM & $0.74 \%$ & $0.44 \%$ \\
\hline
\end{tabular}

The predominant age group for STH infection was found in 7-9 years which was statistically highly significant (P - 0.0019) (Table 2). By contrast, in the control group it was not statistically significant (P - 0.13). This finding is in agreement with Paul et al. (1999) study who also found maximum prevalence in this group.

The prevalence of helminthic infection was seen from 1 year onwards, but decreased in the 5-7 years and reached a peak in 7-9 years age. A. lumbricoides and T. trichiura infection was seen in all age groups. A. lumbricoides was more common in 7-9 years, whereas T. trichiura infection was more in 5-7 years (Table 2). Hookworm infection was seen only in six children, of which 2 were in the study group and 4 in the control group.

Male preponderance was found compared to females in the present study. However, it was not statistically significant (P - 0.076) in the study as well as in the control groups (P - 0.57). Among this, $54 \%$ were male and $46 \%$ were female children. A. lumbricoides and $\mathrm{T}$. trichiura infections were more common in male children. By contrast, H. nana was more common in female children. However, Sex preponderance was not seen with hookworm infection. 


\begin{tabular}{|c|c|c|c|c|c|c|c|c|c|}
\hline \multirow{3}{*}{$\begin{array}{l}\text { AGE } \\
\text { IN } \\
\text { YEAR } \\
\text { S }\end{array}$} & \multirow{3}{*}{$\begin{array}{c}\text { TOTAL } \\
\text { SAMPL } \\
\text { ES }\end{array}$} & \multicolumn{8}{|c|}{ POSITIVE CASES } \\
\hline & & \multirow{2}{*}{$\begin{array}{l}\text { TOTAL } \\
\text { POSITI } \\
\text { VE } \\
(\%)\end{array}$} & \multicolumn{2}{|c|}{$\begin{array}{c}\text { SEX } \\
\text { DISTRIBUTION }\end{array}$} & \multirow{2}{*}{$\begin{array}{l}\text { A. } \\
\text { LUMBRIC } \\
\text { OIDES } \\
(\%)\end{array}$} & \multirow{2}{*}{$\begin{array}{c}\text { T. } \\
\text { TRICHI } \\
\text { URA } \\
\\
(\%)\end{array}$} & \multirow{2}{*}{$\begin{array}{c}\text { HOOK } \\
\text { WORM } \\
(\%)\end{array}$} & \multirow{2}{*}{$\begin{array}{l}\text { H. } \\
\text { NANA } \\
(\%)\end{array}$} & \multirow{2}{*}{$\begin{array}{c}\text { E. } \\
\text { VERMICU } \\
\text { LARIS } \\
\\
(\%)\end{array}$} \\
\hline & & & $\begin{array}{l}\text { MALE } \\
\text { (\%) }\end{array}$ & $\begin{array}{l}\text { FEMAL } \\
\text { E } \\
(\%)\end{array}$ & & & & & \\
\hline $1-3$ & 112 & $\begin{array}{c}23 \\
(19 \%)\end{array}$ & $\begin{array}{c}12 \\
(50 \%)\end{array}$ & $\begin{array}{c}11 \\
(50 \%)\end{array}$ & $\begin{array}{c}19 \\
(81 \%)\end{array}$ & $\begin{array}{c}07 \\
(38 \%)\end{array}$ & $\begin{array}{c}00 \\
(00 \%)\end{array}$ & $\begin{array}{c}00 \\
(00 \%)\end{array}$ & $\begin{array}{c}00 \\
(00 \%)\end{array}$ \\
\hline 3-5 & 84 & $\begin{array}{c}31 \\
(36 \%)\end{array}$ & $\begin{array}{c}14 \\
(47 \%)\end{array}$ & $\begin{array}{c}17 \\
(53 \%)\end{array}$ & $\begin{array}{c}23 \\
(74 \%)\end{array}$ & $\begin{array}{c}16 \\
(50 \%)\end{array}$ & $\begin{array}{c}01 \\
(03 \%)\end{array}$ & $\begin{array}{c}04 \\
(8 \%)\end{array}$ & $\begin{array}{c}01 \\
(03 \%)\end{array}$ \\
\hline $5-7$ & 54 & $\begin{array}{c}18 \\
(28 \%)\end{array}$ & $\begin{array}{c}08 \\
(47 \%)\end{array}$ & $\begin{array}{c}10 \\
(53 \%)\end{array}$ & $\begin{array}{c}12 \\
(63 \%)\end{array}$ & $\begin{array}{c}09 \\
(53 \%)\end{array}$ & $\begin{array}{c}00 \\
(00 \%)\end{array}$ & $\begin{array}{c}03 \\
(16 \%)\end{array}$ & $\begin{array}{c}00 \\
(00 \%)\end{array}$ \\
\hline 7-9 & 65 & $\begin{array}{c}31 \\
(48 \%)\end{array}$ & $\begin{array}{c}17 \\
(53 \%)\end{array}$ & $\begin{array}{c}14 \\
(47 \%)\end{array}$ & $\begin{array}{c}25 \\
(82 \%)\end{array}$ & $\begin{array}{c}13 \\
(38 \%)\end{array}$ & $\begin{array}{c}00 \\
(00 \%)\end{array}$ & $\begin{array}{c}02 \\
(06 \%)\end{array}$ & $\begin{array}{c}00 \\
(00 \%)\end{array}$ \\
\hline $9-14$ & 135 & $\begin{array}{c}55 \\
(37 \%)\end{array}$ & $\begin{array}{c}35 \\
(66 \%)\end{array}$ & $\begin{array}{c}20 \\
(34 \%)\end{array}$ & $\begin{array}{c}42 \\
(76 \%)\end{array}$ & $\begin{array}{c}21 \\
(39 \%)\end{array}$ & $\begin{array}{c}01 \\
(06 \%)\end{array}$ & $\begin{array}{c}01 \\
(06 \%)\end{array}$ & $\begin{array}{c}00 \\
(00 \%)\end{array}$ \\
\hline $\begin{array}{c}\text { TOT } \\
\text { AL }\end{array}$ & 450 & $\begin{array}{r}158 \\
(35 \%)\end{array}$ & $\begin{array}{c}86 \\
(54 \%)\end{array}$ & $\begin{array}{c}72 \\
(46 \%)\end{array}$ & $\begin{array}{c}121 \\
(75 \%)\end{array}$ & $\begin{array}{c}66 \\
(41 \%)\end{array}$ & $\begin{array}{c}02 \\
(03 \%)\end{array}$ & $\begin{array}{c}10 \\
(02 \%)\end{array}$ & $\begin{array}{c}01 \\
(0.22 \%)\end{array}$ \\
\hline
\end{tabular}

There were more positives among boys when compared to girls. However the prevalence was higher among girls (40\%) when compared to boys (36\%). But it was statistically not significant (P 0.076).

The prevalence of STH was more in urban (36\%) compared to rural population (32\%), however statistically it was not significant $(\mathrm{P}$ 0.35). This finding was in contrast with Usha C. Parekh et al. (1972) in urban (39\%) and rural (43\%). In the control group, 6 and 15 children were positive for one or more STH form rural and urban background, respectively. As in the cases, it was also not statistically significant (P 0.82 ). The prevalence of hookworm was seen only in $0.44 \%$ of the children.

\begin{tabular}{|c|c|c|c|}
\hline \multicolumn{4}{|c|}{ TABLE 3. DISTRIBUTION OF HELMINTHIC INFECTION IN } \\
\hline $\begin{array}{c}\text { SL. } \\
\text { NO }\end{array}$ & SOCIALERENT SOCLOSO & $\begin{array}{c}\text { Aggarwal et } \mathrm{al}^{7}{ }^{7} \\
(1972)\end{array}$ & $\begin{array}{c}\text { PRESENT } \\
\text { STUDY } \\
(2004)\end{array}$ \\
\hline 1 & LOWER CLASS & $137(36 \%)$ & $65(38 \%)$ \\
\hline 2 & MIDDLE CLASS & $63(21 \%)$ & $93(34 \%)$ \\
\hline 3 & HIGHER CLASS & $1(3 \%)$ & NIL \\
\hline
\end{tabular}

The prevalence of helminthic infection was highest in the lower socioeconomic status followed by the middle socio-economic status. However, none of the children in high socio-economic status was positive (Table 3). In the control group $4 \%$ and $17 \%$ of children were found positive in the lower socio-economic status and the middle socio-economic status respectively. While the difference among the socio-economic groups was statistically not significant in cases (P - 0.208), in the control group, it was statistically significant ( $\mathrm{P}$ - 0.012). The same finding, also observed by Agarwal et al. (1972) showed the highest prevalence in the low socio-economic status followed by the middle socio-economic status and least in the high socio-economic status (Table 3). 
FIGURE. 4 COMPARISON OF SENSITIVITY OF DIRECT WET MOUNT, SATURATED SALT FLOATATION, FORMALIN-ETHER SEDIMENTATION AND KATO-KATZ TECHNIOUES.

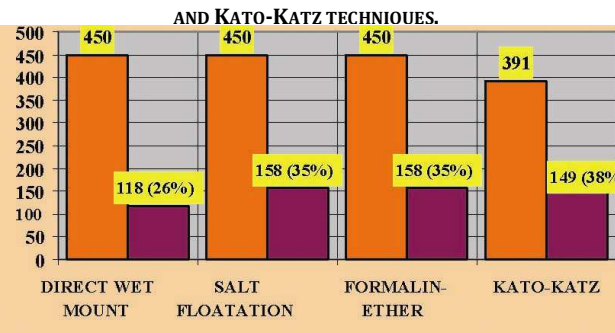

The stool specimens were processed by direct wet mount and concentration methods like saturated salt floatation and formalin-ether sedimentation methods and by Kato-Katz semiquantitative method eggs in the preparation were counted to determine the intensity of infection. In the saturated salt floatation and formalin-ether sedimentation techniques, 35\% children were found positive (both sensitivity and specificity was $100 \%$ ) when compared to the direct wet mount method, where only $26 \%$ were positive, the sensitivity was only $74.49 \%$ and specificity was $100 \%$. These concentration techniques helped to detect overall $9 \%$ more positives which were not detected by direct wet mount preparation (Figure 4). The positive predictive value was $100 \%$ in all the three techniques.

Similarly, in the control group, the sensitivity of direct wet mount, saturated salt floatation and formalin-ether sedimentation techniques were $63.15 \%, 100 \%$ and $100 \%$ respectively and the specificity was $97.46 \%, 100 \%$ and $100 \%$ respectively. The positive predictive value was $85.71 \%$ in the wet mount technique whereas it was $100 \%$ in both the concentration techniques.

Out of 450 clinical samples, only 391 specimens were processed by Kato-Katz semiquantitative technique. Fifty nine stool specimens were loose or watery in consistency and hence could not be processed by this method, as the template hole could not hold loose or watery stool specimens. Out of 391 samples examined 38\% were found positive (Figure 4). This technique helped to detect overall $12 \%$ more positives which were not detected by direct wet mount preparation

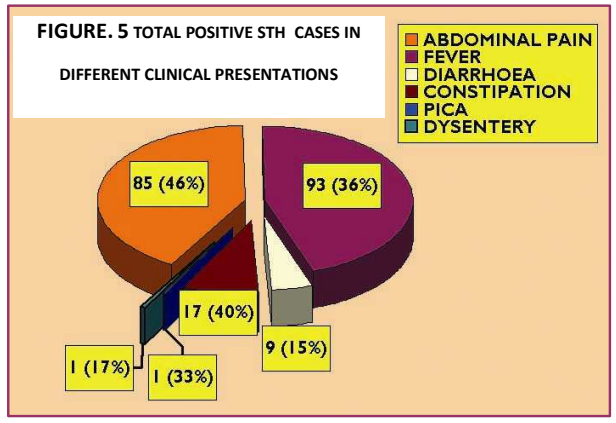

Out of 450 specimens from the study group maximum children presented with abdominal pain, (Figure 5 and Table 4). The present study correlates with Daniel, S. Blumenthal. \& Myron, G. Schultz (1975), who also showed that $48 \%$ of children had abdominal pain out of 21 children screened, who harboured helminths. Fever is the second most common symptom. Low-grade fever is the classical presentation in STH and other intestinal helminths.

Daniel, S. Blumenthal. \& Myron, G. Schultz (1975) showed fever in 38\% of 21 children examined suffering from ascariasis in their study. This is followed by diarrhoeic presentation; Louw (1966) conducted a study on abdominal findings like watery stools in $28 \%$ out of 68 cases. Only about 8\% children had constipation, Daniel, S. Blumenthal. \& Myron, G. Schultz. (1975), reported prevalence of intestinal obstruction in children infected with Ascaris from Southeastern United States and obstipation (absolute constipation) for 24 hours was found in $43 \%$ patients out of 21 children screened. Out of 3 children presented with pica one child was found positive for A. lumbricoides (Figure 5 and Table 4). 


\begin{tabular}{|c|l|c|c|c|c|}
\hline \multicolumn{7}{|c|}{ TABLE 4. DIFFERENT CLINICAL PRESENTATION } \\
\hline $\begin{array}{c}\text { SL. } \\
\text { NO }\end{array}$ & $\begin{array}{c}\text { CLINICAL } \\
\text { PRESENTATION }\end{array}$ & $\begin{array}{c}\text { NUMBER } \\
\text { OF CASES }\end{array}$ & POSITIVE & $\begin{array}{c}\text { SENSITI } \\
\text { VITY }\end{array}$ & $\begin{array}{c}\text { SPECIFI } \\
\text { CITY }\end{array}$ \\
\hline 1 & ABDOMINAL PAIN & $185(41 \%)$ & $85(46 \%)$ & $53.79 \%$ & $65.75 \%$ \\
\hline 2 & FEVER & $261(47 \%)$ & $93(36 \%)$ & $53.86 \%$ & $42.46 \%$ \\
\hline 3 & DIARRHOEA & $59(11 \%)$ & $9(15 \%)$ & $5.69 \%$ & $82.87 \%$ \\
\hline 4 & CONSTIPATION & $43(8 \%)$ & $17(40 \%)$ & $10.75 \%$ & $91.09 \%$ \\
\hline 5 & PICA & $3(0.66 \%)$ & $1(0.22 \%)$ & -- & -- \\
\hline 6 & DYSENTERY & $6(1 \%)$ & $1(17 \%)$ & $0.63 \%$ & $98.63 \%$ \\
\hline
\end{tabular}

A total of 6 children had dysentery, of which one male child was positive for a mixed infection with A. lumbricoides and T. Trichiura (Figure 5 and Table 4). Callender et al. (1993) studied the developmental levels of young children with $\mathrm{T}$. trichiura dysentery syndrome (TDS) in 19 children and the most severe form of $\mathrm{T}$. trichiura infection is characterised by chronic, mucoid bloody diarrhoea. These children had serious lag in the development of 16 Developmental Quotient Points, stunted growth and were anaemic.

\begin{tabular}{|c|c|c|c|c|}
\hline TYPE OF STH & $\begin{array}{c}\text { POSITIVE } \\
\text { CASES }\end{array}$ & $\begin{array}{c}\text { LIGHT } \\
\text { INFECTION }\end{array}$ & $\begin{array}{l}\text { MODERATE } \\
\text { INFECTION }\end{array}$ & $\begin{array}{c}\text { HEAVY } \\
\text { INFECTION }\end{array}$ \\
\hline A. LUMBRICOIDES & 115 & $98(85 \%)$ & $17(15 \%)$ & $00(00 \%)$ \\
\hline T. TRICHIURA & 62 & $12(19 \%)$ & $26(42 \%)$ & $24(39 \%)$ \\
\hline HOOKWORM & 02 & $00(00 \%)$ & $01(50 \%)$ & $01(50 \%)$ \\
\hline
\end{tabular}

The intensity of infection was calculated by Kato-Katz method in 149 positive cases of the total 391 children screened (Table 5). The intensity of infection was calculated based on the WHO methodology. ${ }^{11}$

\begin{tabular}{|c|c|c|}
\hline \multicolumn{3}{|c|}{$\begin{array}{c}\text { TABLE 6. MEAN INTENSITY AND STANDARD } \\
\text { DEVIATION BY EGGS PER GRAM (EPG) OF } \\
\text { DIFFERENT WORMS }\end{array}$} \\
\hline \multirow{4}{*}{ INFECTION } & $\begin{array}{c}\text { CASES } \\
\text { MEAN/ } \\
\text { STANDARD } \\
\text { DEVIATION }\end{array}$ & $\begin{array}{c}\text { CONTROLS } \\
\text { MEAN/ } \\
\text { STANDARD } \\
\text { DEVIATION }\end{array}$ \\
\hline $\begin{array}{c}\text { A. } \\
\text { lumbricoides }\end{array}$ & $7359.58 /$ & $\begin{array}{c}6214.38 / \\
5223.97\end{array}$ \\
\hline T. trichiura & 7164.94 & $1640.71 /$ \\
& 5510.90 & 2524.84 \\
\hline Hookworm & $3722.5 /$ & $1498.25 /$ \\
& 1358.35 & 404.71 \\
\hline
\end{tabular}

Table 6 presents the Mean and Standard Deviation of intensity of A. lumbricoides, T. trichiura and hookworm infections for cases and control groups. In the study group, the mean ova count for A. lumbricoides was slightly more than T. trichiura and least in hookworm infection. On the contrary, in the control group, the mean eggs count of $\mathrm{A}$. lumbricoides was 5 times more than $\mathrm{T}$. trichiura, and similar to cases, the hookworm mean ova count was lowest in number in the control group also. A notable difference in mean ova count was seen with $T$. trichiura where it was 6 times more in the cases than the control children. Similarly, the difference was also found with hookworm infection. However, between the two groups, there was no such wide variation as for as A. lumbricoides concerned. The mean ova count was almost equal between cases and control groups for A. lumbricoides. On the contrary, there was a wide variation between the two groups for T. trichiura and hookworm. This indicates that A. lumbricoides has a high tendency to shed eggs in large numbers in spite of being asymptomatic in the present study. The high standard deviation values indicate wide variation in the intensity of STH infection. The highest standard 
deviation was found in A. lumbricoides, followed by T. trichiura in both study and control groups.

CULTIVATION OF A. LUMBRICOIDES AND T. TRICHIURA EGGS IN THE SOIL: Initially, the unsegmented ova started growing to the blastomeric stage in about one to two weeks in the soil. In the $3^{\text {rd }}$ or $4^{\text {th }}$ week the larvae showed movement within the eggs. By $5^{\text {th }}$ or $6^{\text {th }}$ week, the first stage Rhabditiform larvae of A. lumbricoides hatched out of the ova (Figure 6, Row 1).

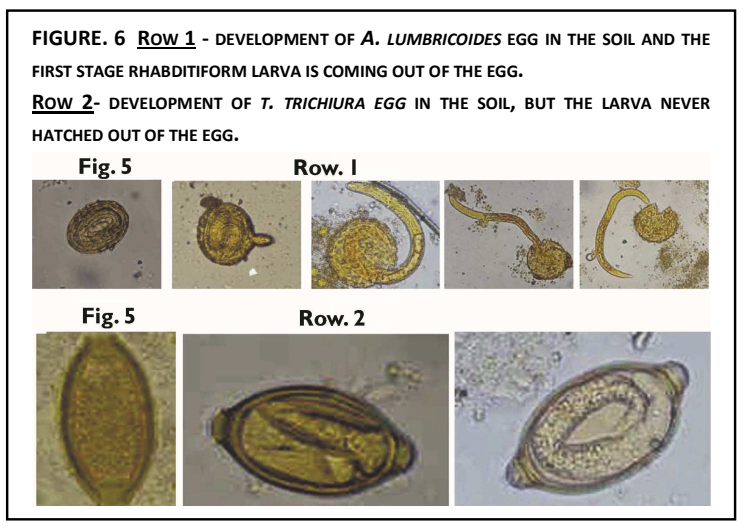

Similarly, the T. trichiura larvae also were grown in the soil. However, the larvae never hatched out of the eggs, though larvae were showing movement within the eggs (Figure 6, Row 2).

The development of these ova were observed under the 10X and 40X objectives everyday by wet mount preparation such as saline and iodine mount. The hatching of A. lumbricoides larvae were seen especially in iodine mount than in saline mount. This may be probably due to an inducing stimulus of iodine on the embryonated eggs to hatch. Surprisingly, the embryonated ova of T. trichiura did not hatch either in the saline or iodine preparation although the larvae were moving vigorously within the ova (Figure 6, Row 2).

DISCUSSION: Out of the 550 stool samples examined 450 were from the study group and 100 were from the control group. All the 450 children of the study group were presented with the classical symptoms of soil-transmitted and other intestinal helminthes. One hundred children were selected in the control group did not have any classical symptoms. Thirty-five per cent from the study group and $21 \%$ from the control group were found positive for any one of the parasites.

Ascaris was more common in the age group of 7-9 year old children, whereas Trichuris was common in 5-7 years. Hookworm eggs were found in only two children from 3-5 and 9-14 years of age group. This finding suggests that ascariasis might be the disease of the urban and hookworm infection is the disease of rural area. Apart from this, most of the children who come to government hospitals are mostly from urban slums, where the people live in overcrowded and unsanitary conditions. On the hand, hookworm infection is more common in rural children, where people have the habits of open-air defaecation and walk barefoot. The high prevalence of STH in school age group could be due the fact that children of that age play outdoors and probably tend to put everything into their mouths, which might be contaminated with faeces. In addition, there is lack of awareness regarding personal cleanliness and hygiene.

Male preponderance was seen with A. lumbricoides and T. trichiura, whereas equal distribution was seen with hookworm. On the contrary females showed preponderance as far as $\mathrm{H}$. nana infection is concerned. The higher prevalence of helminthic infections was perhaps due to more outdoor activity in male than female children.

Maximum stool samples were from urban population compared to rural background. This may be due to the fact that in a developing country like India, urbanisation has resulted from unplanned, uncontrolled and constant migration of people from rural areas in search of job 
living in urban slums without proper sanitary latrines, meagre resources of water supply, garbage disposal, poor health care and hygiene.

The prevalence of hookworm was seen only in $0.44 \%$ of the children because majority of the patients were from the urban setting and usually high prevalence of hookworm infection is seen in rural agricultural population rather than urban dwellers. Hence, the prevalence of hookworm was low in the present study.

The prevalence of helminthic infection was highest in the lower socio-economic status followed by the middle socio-economic status. However, none of the children in high socioeconomic status was positive. This is mainly because of poverty, illiteracy, bad hygiene, poor housing conditions, bigger family sizes with small places to live, and women marrying at an early age with bearing more children. Hence, there will be more chances of infection spreading within the families due to unhygienic practices.

Routine examination of faecal samples using direct wet mount of saline and iodine preparations has obvious limitations. In direct wet mount preparation, there is a chance of missing light infections, where helminthic load is low and the relative intensity of eggs cannot be determined. The advantage of concentration methods over the direct wet mount is that light and intensity of infections can be better appreciated. In Kato-Katz semiquantitative technique we can detect very light infections and also intensity of infection. Consequently, we can treat light and asymptomatic children and women of child bearing age. Thus the concentration techniques are better than the direct wet mount technique for authentic and reliable results. The application of either saturated salt floatation or formalin-ether sedimentation technique in conjunction with direct wet mount preparation is proved to be the best.

The clinical manifestations of STH and other intestinal helminths are protean in nature. The child may have many worms in the intestine but still asymptomatic. Among the six classical symptoms of STH, abdominal pain and fever were the best predictors of STH infection, sensitivity and specificity (Abdominal pain-53.79\% \& 65.75\% and Fever 58.86\% \& 42.46\% respectively). On the other hand, constipation and diarrhoea were moderate predictors of STH (sensitivity $10.75 \%$ \& $5.69 \%$ and specificity $91.09 \%$ \& $82.87 \%$ respectively). However, pica and dysentery were poor predictors of STH (sensitivity $0.63 \% \& 0.63 \%$ and specificity $99.31 \%$ and 98.63\% respectively).

It was surprising to see that among 100 children in the control group, $21 \%$ were found positive for one or more STH infection in spite of being asymptomatic (Figure 2). Hence, it may be prudent to treat all children with anthelmintics whether symptomatic or asymptomatic. If not treated, the asymptomatic children, in due course might develop the complications associated with STH infections like anaemia, malnutrition, growth retardation etc. Moreover, these children are a dangerous silent source of infection to others. Apart from the soiltransmitted and other intestinal helminths $9 \%$ of children showed protozoal infections like Entamoeba histolytica, Giardia lamblia, and Balantidium coli.

CONCLUSION: Concentration techniques like salt floatation and formalin-ether are the best diagnostic tool to get authentic and reliable results and to rule out fallacious inference caused by relying only on direct wet mount preparation. Kato-Katz, a semi quantitative technique is the best diagnostic method to know the prevalence and intensity of the soil-transmitted helminthic infection. The technique is simple, rapid, reliable and mild infections can also be detected. No special equipment is needed other than the microscope, so this can be performed in the field survey as well. This technique does not need the expertise anyone can easily be trained by this 
technique. Thereby prevent the transmission of parasitic infections in the community by giving appropriate treatment and providing sanitary facilities with health education.

The availability of single dose broad spectrum oral anthelminthic drug has simplified treatment and made control programmes logistically feasible. Hence, the corner stone of WHO comprehensive package for control of morbidity due to STH infections is mass anthelminthic therapy for high risk groups of children and women of child bearing age with health education as short term strategies while long term control measures include adequate sanitation, proper drinking water facility, proper defecation sites, wastage disposal and personal hygiene and community participation is suggested as an effective and appropriative preventive programs in primary health care and thus aimed towards achieving Health for all by 2000 AD.

ACKNOWLEDGEMENTS: We have great pleasure in expressing our sincere thanks and gratitude to Prof. Bharathi K for her constant inspiration and under whose able guidance and supervision, this work was carried out. We express profound sense of gratitude and indebtedness to Prof. Meera D. Meundi, Prof. Nagaraj E.R., Prof. Nagarathnamma T., Dr. Chandrakala Rajanna H.S., for their constant suggestions \& encouragement and their timely advice. We sincerely acknowledge Prof. Shivarudrappa A.S. for his kind support for taking the photographs, Prof. Umapathy B.L., for in depth proof correction. Dr. Shashikiran. M and Dr. Umesh. Y Ramadurg for their immense advice for statistical workup. Prof. Manjuntha M.L. (Former Principal of Sri Jagadguru Renukacharya College, Bangalore) for language correction. Our colleagues and the technical staff for their faithful and moral support at various stages of dissertation work. Our special thanks to everyone in the department of Paediatrics who helped in the sample collection for the study. Lastly, our sincere thanks to all the patients and control children who were the subject of the study and without their great cooperation, the study would have been impossible. This work was presented as a poster presentation in part in abstract form at the 29th Annual Congress of Indian Association of Medical Microbiologists, Chennai, Tamilnadu, India, 19-23 October 2005.

\section{REFERENCES:}

1. Ananthakrishnan, S., Nalini, P. \& Pani, S. P. (1997). Intestinal geohelminthiasis in the developing world. National Medical Journal of India 10, 67-71.

2. Monica Cheesbrough, (1999). Identification of helminth eggs and larvae found in faeces. In District Laboratory Practice in Tropical Countries, pp. 208-220. Edited by Monica Cheesbrough Part I. United Kingdom: University of Cambridge press, Cambridge.

3. World Health Organization, (1992). Cellophane faecal thick smear for diagnosis of intestinal schistomiasis (Kato-Katz technique). In Basic Laboratory Methods in Medical Parasitology, pp. 25-32. Edited by WHO. $1^{\text {st }}$ Indian Edition. WHO, Geneva.

4. Bora, D., Singh, S. K., Bhagat, H., Sharma, R. C. \& Datta, K. K. (2001). Status of SoilTransmitted helminthic infections in India-observations on sample surveys using Kato-Katz technique. J Commun D 33(2), 110-115.

5. Paul, I., Gnanamani, G. \& Nallam, N. R. (1999). Intestinal helminth infections among school children in Visakhapatnam. Indian J Pediatr 66, 669-673.

6. Usha, C. Parekh., Naik P. A., Udani, P. M. \& Shah, P. M. (1972). Parasitic infestations in preschool children of Urban and Rural Communities. Indian Pediatrics 9, 332-336.

7. Agrawal, O. P., Gulati, P. V. \& Bhujwala, R. A. (1972). Comparative prevalence and related symptomatology study of enteric helminths in Delhi urban and semi-urban primary schools. Indian J Prev Soc Med 3, 164-166. 
8. Daniel, S. Blumenthal. \& Myron, G. Schultz. (1975). Incidence of intestinal obstruction in children infected with Ascaris lumbricoides. American Journal of Tropical Medicine and Hygiene 24, 801-805.

9. Louw, J. H. (1966). Abdominal complication of Ascaris lumbricoides infestation in children. British Journal of Surgery 53, 510-521.

10. Callender, J., Grantham-McGregor, S., Walker, S. \& Cooper, E. (1993). Developmental levels and nutritional status with the Trichuris dysentery syndrome. Transactions of the Royal Society of Tropical Medicine and Hygiene 87, 528-529.

11. World Health Organization. Guidelines for the evaluation of soil-transmitted helminthiasis and schistosomiasis at community level, pp. 30. WHO, Geneva. (documentWHO/CTD/SIP/98.1). 